\title{
Investigation of Instability Mechanisms in a Laboratory Scale $\mathrm{GH}_{2} / \mathrm{GO}_{2}$ Combustor
}

\author{
Abhinav Dasari*, Logan W. White* and Mirko Gamba ${ }^{\dagger}$ \\ The University of Michigan, Department of Aerospace Engineering, 1320 Beal Avenue, Ann Arbor, MI 48109
}

\begin{abstract}
This work investigates the properties of self-sustained unsteady flames in a moderatepressure single, shear coaxial injector combustor. Strong flowfield and flame structure modification is observed as a result of the low amplitude pressure fluctuation established in the combustion chamber. The flame front is observed to undergo a periodic change in structure, with near complete extinction and reignition following ejection events. Observations from performing experiments at varying chamber lengths suggest that the instability is thermoacoustic in nature. Corresponding mixing studies of variable-density non-reacting shear coaxial jets demonstrate the presence of self-excited hydrodynamic instabilities in the form of side jets, which could potentially be linked to the unsteady behavior in reacting cases.
\end{abstract}

\section{Nomenclature}

$\begin{array}{ll}\rho & \text { Density } \\ v & \text { Velocity } \\ D & \text { Diameter } \\ L & \text { Length } \\ P & \text { Pressure } \\ \dot{m} & \text { Mass flow rate } \\ S & \text { Density ratio } \\ R & \text { Velocity ratio } \\ R e & \text { Reynolds num } \\ \phi & \text { Equivalence R } \\ J & \text { Momentum flux } \\ & \\ \text { Subscript } \\ i & \text { Inner stream } \\ o & \text { Outer stream } \\ c & \text { Chamber }\end{array}$

\section{Introduction}

Combustion instabilities, in the context of rocket propulsion, were first observed in the $1930 \mathrm{ss}^{1}$ According to Lord Rayleigh, the constructive coupling between an unsteady heat release rate and acoustic waves was the cause of such instabilities. ${ }^{2}$ Crocco and Cheng $^{3}$ laid the theoretical foundations for analysis of combustion instabilities, and despite advances over the years, ${ }^{4,5}$ no complete theory is yet available.

During unstable combustion, the frequency spectra of combustion in chamber shows distinct frequencies that contain large amounts of energy. These organized pressure oscillations often result in catastrophic failure

${ }^{*}$ Graduate Student, Department of Aerospace Engineering, 1320 Beal Ave., University of Michigan, Ann Arbor, MI 48109, Student Member AIAA.

${ }^{\dagger}$ Assistant Professor, Department of Aerospace Engineering, 1320 Beal Ave., University of Michigan, Ann Arbor, MI 48109, Member AIAA. 
of the engine. ${ }^{6}$ The F-1 engine, developed to satisfy the heavy lift requirement of the Apollo Program, suffered serious erosion and damage of the injector face during its development process due to the presence of strong instabilities. The design of modern engines, with high density of energy release in a volume with relatively low losses, favors the excitation and sustenance of oscillations. ${ }^{1}$ In gas turbines, development of high bypass engines created conditions favorable for low frequency longitudinal vibrations to exist, which could not be eliminated be simple geometry changes. With the recent thrust towards lean, low-temperature premixed combustion for emission reduction, the potential for instabilities in gas turbines increases. The presence of a wide variety of physical phenomena make the characterization and prediction of instabilities difficult.

Research performed at the Michigan Single Element Injector Facility aims to provide an experimental benchmark for guidance and validation in the development of new theoretical and computational models. The facility can support steady and unsteady shear coaxial $\mathrm{GH}_{2} / \mathrm{GO}_{2}$ jet flames under both atmospheric and elevated pressure conditions. In recent work ${ }^{7}$ we have demonstrated the presence of self-sustained unsteady combustion at fuel lean conditions. The aim of this work is to further investigate the properties of and mechanisms responsible for the observed combustion dynamics.

A significant amount of work has been done in the past to explore the dependence of instability on equivalence ratio. ${ }^{8-13}$ At our facility, the flame was found to be unstable when equivalence ratio was reduced below an equivalence ratio of 0.3 for a $\mathrm{GH}_{2} / \mathrm{GO}_{2}$ system. Fritsche et al. ${ }^{9}$ found that the system experienced higher levels of instability as the equivalence ratio was moved away from a stoichiometric mixture fraction. At a low limit of about $\phi=0.5$, the pressure oscillations were observed to decrease again as the system approached lean blowout. Increase in pressure drop across the flame with a decrease in equivalence ratio was found to be the mechanism responsible for instabilities. Bellows et al. ${ }^{14}$ identified vortex roll-up and flame lift off to be responsible for change in flame shape during transition from stable to unstable combustion, and both these mechanisms were related to velocity fluctuations at the entrance to the burner. Lieuwen determined that inlet velocity played a major role in determining in determining limit cycle amplitudes. ${ }^{15}$ Using a premixed gas turbine combustor with chamber pressures ranging from 1 to $10 \mathrm{~atm}$, pressure oscillations on the order of $1.5 \%$ were recorded at frequencies raging from 100 to $700 \mathrm{~Hz}$. In classical literature, combustion is considered stable as long as the pressure fluctuations do not exceed $5 \%$ of the mean chamber pressure. ${ }^{16}$ But even in our initial experiments, fluctuations with amplitudes as low as $1.5 \%$ of the mean pressure were seen to introduce strong flow field and flame structure modifications, causing the flame to undergo cyclic extinction and reignition. In Lieuwen's work, a hysteresis effect was observed at lower inlet velocities, where the stability level was found to be dependent on the direction of velocity change. Over the higher inlet velocity range, amplitudes tended to be higher. Spontaneous transition from stable to unstable combustion was observed and the background combustor noise was suggested to be responsible for forcing the system and introducing cyclic variability. Broda et al. investigated the effect of equivalence ratio and temperature on stability level and flame shapes and observed pressure oscillations of up to $20 \%$ of mean chamber pressure in their gas turbine combustor. ${ }^{8}$ Similar to Fritsche et al., they too observed the level of instability increasing as the equivalence ratio was moved away from stoichiometric, and pressure oscillations beginning to decrease when the ratio was lowered further and system approached blowout. As the system transitioned into unstable regime, the flame was seen to become shorter and moved back into the recirculation zone. Strong interactions between flame dynamics and flow oscillations were determined to be a possible cause for the instabilities. Understanding how a shear coaxial injection system, which are used in a variety of rocket engine configurations, ${ }^{17}$ such as the RS-68 and Vulcan 2, reacts to changes in equivalence ratio, and how these changes affect the flowfield and flame structure is a major focus of our present work.

Combustion instabilities are usually classified into three different categories. ${ }^{18}$ Low frequency instabilities, in the range of a few hundred hertz, can occur due to the coupling of combustion with the injector, causing fluctuations in the propellant injection. Intermediate frequency instabilities in the range of several hundred to thousand hertz can have many different causes, entropy wave caused by cyclic mixture ratio variation being one of them. High frequency or thermoacoustic instability generally lies in the range of thousands of hertz and is usually caused by the excitation of an acoustic eigenmode of the chamber by the combustion process. High frequency instabilities, due to the energies involved, can be very destructive. Initial data points towards instabilities in our rocket combustor being primarily thermoacoustic in nature, with the presence of either a low frequency or an entropy mode too. The mechanism of coupling, whether acoustic pressure or velocity, which modulates the heat release rate is still debatable. ${ }^{19-21}$ With an array of diagnostic techniques, including high frequency pressure measurements, high frequency chemiluminescence imaging and Planar Laser Induced Fluorescence (PLIF), we aim to better understand and characterize this unsteady behavior. 


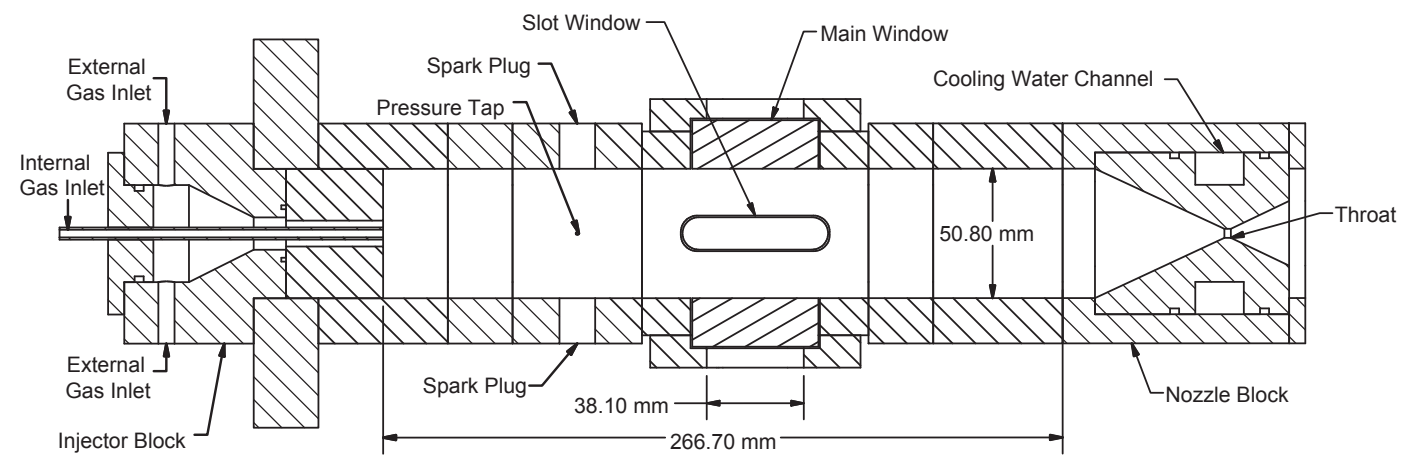

(a)

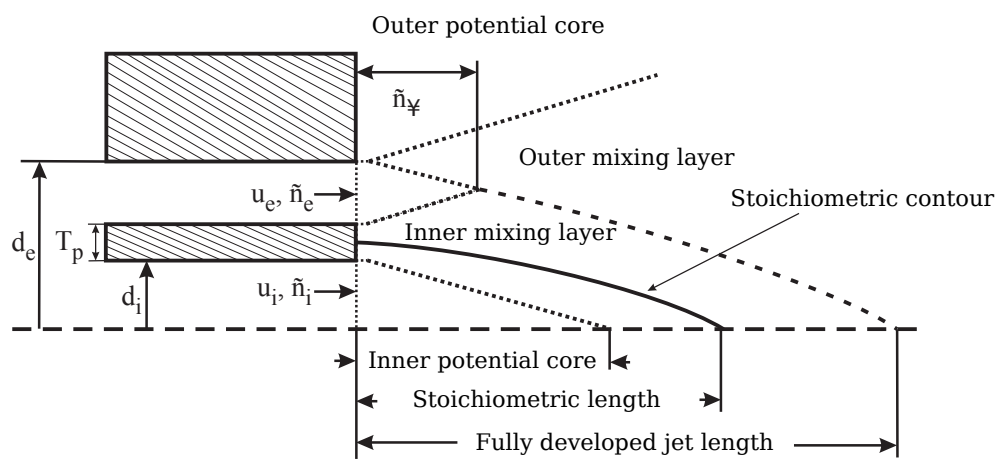

(b)

Figure 1. (a)Schematic diagram of the Michigan Single Element Injector Facility, and (b) of the shear coaxial jet. From Schumaker (2009). ${ }^{23}$

\section{Experimental Setup}

Experiments for understanding the characteristics of self-sustaining unsteady combustion phenomena and the corresponding non-reacting mixing studies ${ }^{22}$ were performed at the Michigan Single Element Injector Facility. This section describes the experimental configuration and diagnostic techniques used in this study.

\section{A. Test Apparatus}

The Michigan Single Element Injector Experiment, originally designed and sized by Schumaker ${ }^{24,25}$ based on work done at Penn State and NASA Marshall, ${ }^{26-28}$ is a laboratory scale gas phase rocket engine model capable of operations at chamber pressures up to $10 \mathrm{~atm}$. The facility was originally developed to study mixing in reacting and non-reacting coaxial jets under steady operation, and has been described in detail by Schumaker. ${ }^{25}$ A schematic diagram of the facility is shown in Figure 1(a).

The modular rocket combustor has optical access windows for laser-based diagnostics, an injection block with a single shear coaxial jet injector located at its center, and an actively cooled nozzle block. It is machined out of C145 Tellurium-Copper. Figure 1(b) is a schematic layout of the coaxial jet, highlighting some of its fluid dynamic features. The chamber itself has a square cross section of $50.8 \mathrm{~mm} \times 50.8 \mathrm{~mm}$ (with rounded corners) with a maximum length of $267 \mathrm{~mm}$, and is composed of several instrumented, interchangeable modules. The total length of the chamber can be varied based on the number of modules used. The watercooled nozzle block terminates the chamber. The heating capacity of the thermal mass of the engine limits the test time during reacting cases as the entire system is not actively cooled.

A $90 \mathrm{~mm}$ long section with quartz windows on all sides provides optical access to the chamber. There are two narrow windows for laser access on a set of opposite sides, while the two other sides house full-width windows for imaging. The optical section can be placed at different longitudinal positions to characterize different flame regions. For the purpose of this present work, the section was always placed at the base of 
the chamber, immediately downstream of the injector.

The external temperature of the engine is monitored by K-type thermocouples, and the temporal evolution of pressure is monitored using a Kulite ETM-375, a Kistler 6061B with a Type 5010 charge amplifier and a Cooper PTG-404-A pressure transducers. Data from the transducers is acquired at $10 \mathrm{kHz}$.

The injector block can house coaxial propellant delivery tubes of different inner and outer diameters to facilitate operation over a range of conditions. For reacting cases, the inner tube delivers the oxidizer $\left(\mathrm{O}_{2}\right)$ and the surrounding annulus delivers the fuel $\left(\mathrm{H}_{2}\right)$. For studies involving mixing in variable density jets, inert gases like $\mathrm{He}, \mathrm{N}_{2}$ and $\mathrm{Ar}$ are used, and the required gases are injected through either the inner tube or the surrounding annulus depending on the density ratio required. More details on the experimental configuration use for the non-reacting, variable-density experiments is documented in the companion work. ${ }^{22}$ For all cases in the present study, the inner tube has an inner diameter $D_{i}$ of $3.66 \mathrm{~mm}$ and an outer diameter of $4.76 \mathrm{~mm}$, and the annulus has a diameter $D_{o}$ of $6.73 \mathrm{~mm}$.

The gases are delivered to the rocket chamber by a set of remotely operated solenoid valves. A system of pressure regulators, needle valves, choked orifices and pressure transducers is used to regulate the mass flow rates. The entire system is controlled by a LabVIEW-based controller.

\section{B. PLIF System}

In reacting cases, the instantaneous location of the reaction zone is approximately marked by $\mathrm{OH}$ planar laser-induced florescence (PLIF) imaging, while the overall flame structure is imaged by detecting $\mathrm{OH}^{*}$ chemiluminescence. A typical system composed of a tunable dye laser (Continuum ND 6000) pumped by the second harmonic of a Nd:YAG laser (Spectra Physics Pro 250) is used to excite the A-X $(1,0) \mathrm{Q}_{1}(7)$ transition line of $\mathrm{OH}$ near $283 \mathrm{~nm}$. The dye laser is operated using Rhodamine 590 dye, and its output is doubled by a harmonic generator (Inrad Optics Autotracker III). A UV harmonic separator is used to isolate the desired wavelength.

An intensified CCD camera (Andor iStar), equipped with a $100 \mathrm{~mm} f / 2.8 \mathrm{UV}$ lens is used to carry out the fluorescence imaging. The camera is arranged with its line-of-sight perpendicular to the propagation of laser sheet through the combustor. The field of view is approximately $44 \mathrm{~mm} \times 44 \mathrm{~mm}$. The ICCD camera is gated to $200 \mathrm{~ns}$ and a $310 \mathrm{~nm}( \pm 10 \mathrm{~nm})$ bandpass filter is used to block unwanted light. With run times of 12 seconds and a frame rate of $5 \mathrm{~Hz}$, at least 30 useful images are captured during each run, after dropping data from the initial startup transients. Non-uniformities in the laser sheet are accounted for by the use of standard background and sheet correction schemes. ${ }^{29}$

Chemiluminescence imaging is done using a high speed CMOS camera (Phantom v771 and Phantom v9.1) equipped with a Nikon $50 \mathrm{~mm} f / 1.8$ lens at $10 \mathrm{kHz}$.

\section{Toluene PLIF System}

For the non-reacting mixing studies, tracer-based PLIF was used to measure the mole fraction distribution of one of the two streams. Toluene, due to its good fluorescence properties, ${ }^{30,31}$ is used as the tracer. One of the two gas streams is saturated with toluene by bubbling a known mass flow rate through a toluene seeder. The illumination is provided by the fourth harmonic of a Nd:YAG laser (Spectra Physics Pro 250), and the LIF signal is captured with an electron multiplying CCD camera (Andor iXon), equipped with a $100 \mathrm{~mm} f / 2.8$ UV lens and a $310 \mathrm{~nm}( \pm 10 \mathrm{~nm})$ bandpass filter is used to block scattered and other background light. The electron multiplication feature on the EMCCD camera was disabled because sufficient signal was achieved without it. The toluene concentrations used in these experiments were high enough to cause appreciable absorption of the laser intensity between the edges of the interrogation volume. To compensate for this, a Beer's Law absorption correction scheme that uses a ray-tracing algorithm is applied to the processed images. Standard background and sheet correcting schemes are also applied.

\section{Test cases}

Past work at this facility ${ }^{24,25}$ focused on steady, rich cases. The existence of self-sustaining unsteady flames with low-amplitude instabilities under fuel-lean conditions was demonstrated in recent experiments. ${ }^{7}$ In the current study we expand on the range of test cases and diagnostics applied to investigate the system.

Gaseous oxygen and hydrogen are used for reacting cases. Tests were run both at atmospheric and higher pressure (i.e., with the nozzle attached). Runs were made at different equivalence ratios and mass flow rates. 


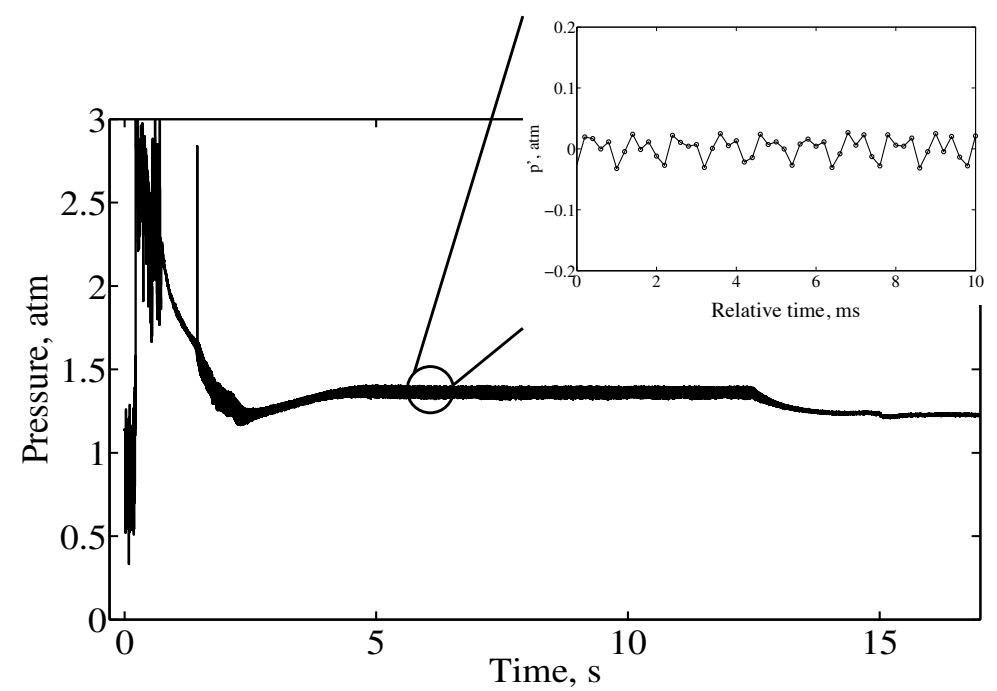

Figure 2. Pressure variation in the rocket chamber during a typical run under unsteady operation. The plot in the inset refers to an enlarge view of the pressure fluctuation measured in the chamber during the stationary portion of the test time. The case shown in the figure is for a reacting case at $\phi=0.1$.

We particularly focus on near-stoichiometric and fuel-lean cases. For most cases, the inner stream Reynolds number $R e_{i}$ varies from 11000 to 25000 and the outer stream Reynolds number $R e_{o}$ varies from 700 to 3000. Fuel-to-oxidizer velocity differences $\Delta v$ range from $-45 \mathrm{~m} / \mathrm{s}$ to $27 \mathrm{~m} / \mathrm{s}$. A summary of the test conditions is provided in Table 1.

For non-reacting cases, $S$ and $R$ were the main parameters considered. Different density ratios are obtained by injecting suitable gases into the inner tube and the surrounding annulus. Experiments were performed at $S$ of $0.14,0.7,1,1.43$ and 6.99 . For each $S, R$ values of $0.5,0.7,1,3.5,6$ and 9 were considered. A more comprehensive description of the non-reacting cases is presented in our companion work. ${ }^{22}$

For the reacting cases, the run time of the rocket is limited to 12 seconds to avoid overheating beyond its maximum tolerable temperature. Non-reacting cases are not limited by rocket heating and data is collected over a period of 30 seconds. In both cases, the data is collected after the start-up transients have terminated. Figure 2 shows the pressure variation during the course of a typical reacting case. The initial spike is caused by the spark plug being fired to ignite the injector. Data between the $6 \mathrm{~s}$ and $12 \mathrm{~s}$ mark is used for processing and analysis.

Table 1. Conditions for reacting test cases

\begin{tabular}{lccccc}
\hline Group & $\phi$ & $\dot{m}(\mathrm{~g} / \mathrm{s})$ & $L_{c}(\mathrm{in})$ & $P_{c}(\mathrm{~atm})$ & $v_{H 2}-v_{O 2}(\mathrm{~m} / \mathrm{s})$ \\
\hline 1 & 0.1 & $0.73,1$ & $7,8,9,11$ & $1.36,1.39$ & $-34.2,-45.1$ \\
2 & 0.2 & 1 & 11 & 1.26 & -42.8 \\
3 & 0.3 & 1 & 11 & 1.19 & -37.8 \\
4 & 0.6 & $0.8,1.2,1.6$ & 11 & $1.29-2.45$ & $-13.4--12.2$ \\
5 & 0.7 & 1 & 11 & 1.33 & -8.8 \\
6 & 0.8 & $0.8,1.2,1.6$ & 11 & $1.05-1.56$ & $-4.6--2.9$ \\
7 & 1.0 & $0.8,1,1.2,1.6$ & 11 & $1.01-2.18$ & $8.3-10.5$ \\
8 & 1.2 & $0.8,1,1.2,1.6$ & 11 & $1.07-2.99$ & $13.8-19.2$ \\
9 & 1.4 & $0.8,1.2,1.6$ & 11 & $1.18-3.47$ & $18.3-27.0$ \\
\hline
\end{tabular}




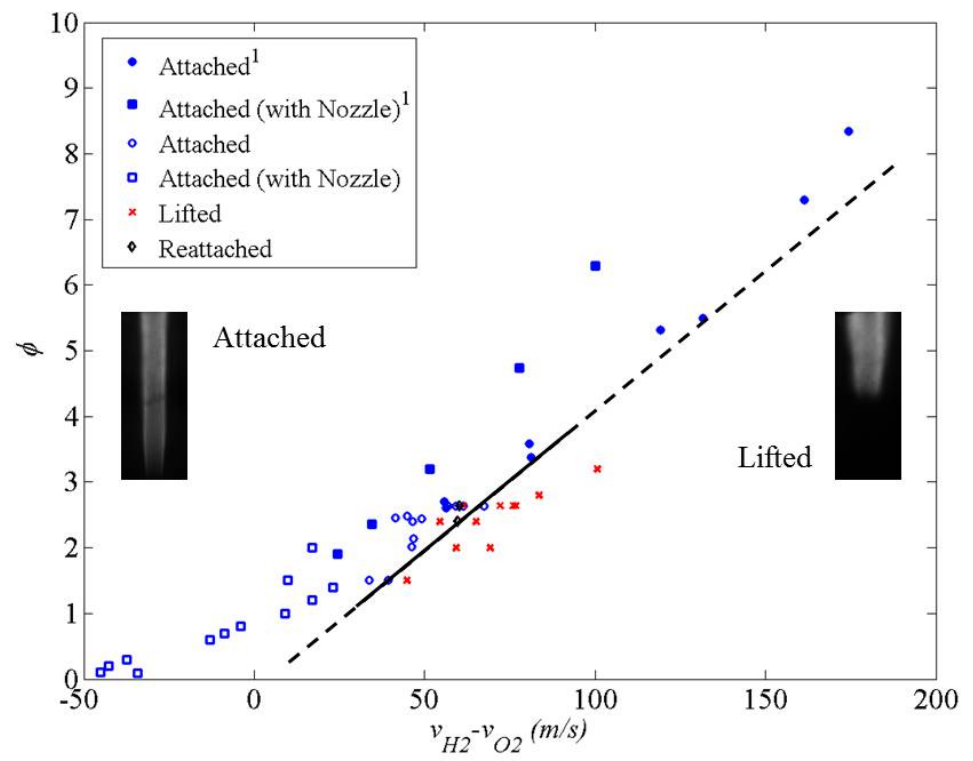

Figure 3. Liftoff Stability map for $\mathrm{O}_{2} / \mathrm{H}_{2}$ shear coaxial turbulent jet flame: dependence on equivalence ratio and fuel-oxidizer velocity difference. Insets are long exposure $\mathrm{OH}^{*}$ chemiluminescence images of an attached and lifted case respectively. ${ }^{1}$ Data from Schumaker ${ }^{25}$

\section{Results and Discussions}

\section{Liftoff stability}

Figure 3 is a liftoff stability map, which summarizes conditions where an attached or lifted flame were observed, of the $\mathrm{O}_{2} / \mathrm{H}_{2}$ shear coaxial jet flame as a function of the equivalence ratio $\phi$ and the fuel-tooxidizer (outer-to-inner) velocity difference $\Delta v=v_{o}-v_{i}$. This figure was compiled from data generated in current and concurrent studies, and from previous work done at the same facility ${ }^{7,23,25}$ for gaseous $\mathrm{O}_{2} / \mathrm{H}_{2}$ cases, both with and without the nozzle. $\Delta v$ was used to correlate the data since it was found to best separate the lifted from the attached cases as seen in the figure. Intermediate cases where the flame would reattach after an initial lifted state were also observed. The reattachment process was possibly associated with a chamber temperature effect. All data shown in this figure refer to cases with a chamber length equal to 9 in, which is here taken to be the baseline chamber length configuration.

\section{Unsteady flame structure}

Previous work done at this facility ${ }^{23}$ considered only very rich mixtures; the present study concentrates on near-stoichiometric and fuel-lean mixtures. During the initial characterization of the combustor, it was observed that going fuel lean while keeping the total mass flow rate constant made the flame go unsteady. The unsteady flame, as visualized by its emission (Figure 4(a)), shows a shorter, broader flame structure as compared to the stable, elongated and orderly global flame structure of the attached case (Figure 4(b)). Visual inspection of the temporal behavior, backed by pressure data, indicates that the flame goes through repeated cycles of growth, contraction, extinction and re-ignition over the test time; flame extinction seems to be global. Despite the measured small amplitude of the pressure fluctuation in these unsteady cases, the impact on the global flame structure and stability is significant. A representative example of the pressure fluctuation $\left(p^{\prime}=p-\bar{p}\right)$ is shown in the inset of Figure 2: a periodic, small amplitude $(\sim 1-2 \%$ of the mean value) pressure oscillation is found. Furthermore, in spite of the periodic extinction/re-ignition cycle, the injector rim appears to get very hot in the (fuel-lean) unsteady case (note the bright white spot marking the location of the injector rim in Figure 4(a)), while it does not appear to significantly heat up for the steady case although it is an attached flame. The hot rim could be responsible for flame re-ignition.

The temporal evolution of the global structure of the flame was investigated through cinematographic $\mathrm{OH}^{*}$ chemiluminescence imaging. Figure 5 shows a time sequence of consecutive chemiluminescence images 


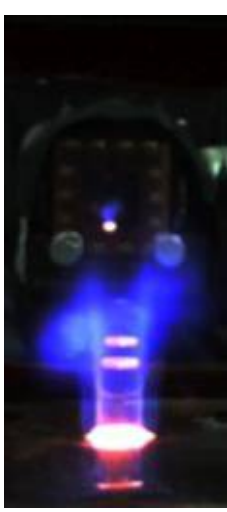

(a)

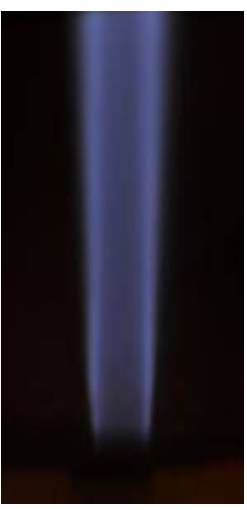

(b)

Figure 4. Long exposure picture (of flame emission) of (a) fuel-lean unsteady $(\phi=0.2)$ and (b) near stoichiometric steady $(\phi=1.5)$ attached flames. (Note: the two horizontal bands in the middle of flame in image (a) are reflections of the hot injector on the back window.)

taken at $10 \mathrm{kHz}$ for an unsteady case generated $\phi=0.3$ and $\Delta v=-38 \mathrm{~m} / \mathrm{s}$. The sequence shows the periodic evolution of the flame front on this unsteady flame. The flame is observed to pulsate generating a vortex-ring-like structure (reminiscent of vortex rings formed in impulsively started jets ${ }^{32}$ ), or simply a "puff", and thus creates a strong ejection of fuel/oxidizer mixture that burns out; the flame then nearly extinguishes only to subsequently reigniting, and thus repeating the entire cycle again. By approximately tracking the trajectory of the vortex-ring-like structure that is clearly visible in the time sequence, we can infer a convection speed of the structure between 15 and $20 \mathrm{~m} / \mathrm{s}$, which is about half of the velocity difference $\Delta v$.

The instantaneous (planar) structure of the flame front was investigated through OH PLIF imaging. A sequence of uncorrelated instantaneous OH PLIF images for the same case of Figure 5 is presented in Figure 6. The PLIF sequence is extracted from the same run of the chemiluminescence sequence of Figure 5 at different stages of the flame evolution cycle; however, it does not correspond to a true consecutive sequence of images (OH PLIF images were acquired at a few $\mathrm{Hz}$ only). The sequence was constructed by selecting instances over the run where the instantaneous $\mathrm{OH}$ structure resembled the global flame structure as typically observed in the chemiluminescence sequence. Thus, we can draw a direct analogy between the flame structure as seen by the chemiluminescence and the OH PLIF. In fact, comparing the two figures we can observe that the chemiluminescence images (which are path integrated) closely capture the flame structure on the mid-plane of the combustion chamber (i.e., injector).

Figure 6(a) corresponds to the flame structure as re-ignition occurs after global extinction of the previous cycle. The initial burning regions then evolve (Figure 6(b)) to form the vortex-ring-like, double-layered reacting system of Figure 6(c). This is the phase of maximum ejection (puff) that is fully reacting. At this early stages of the evolution, multiple flame fronts exist: there is an inner reaction layer associated with the $\mathrm{O}_{2} / \mathrm{H}_{2}$ boundary and an outer layer associated with the $\mathrm{H}_{2}$ stream and the oxygen-rich outer recirculation zones formed by post-combustion gases of the inner flame recirculating at the base of the combustor. The oxygen-rich recirculation region is the result of the overall fuel-lean operation of the combustor, but also by the cyclic global extinction of the flame that allows oxidizer and fuel to escape unburnt and reciruclate in the dead zones of the combustor. The two-layer structure is well-defined at the base of the flame (i.e., just downstream of the injector faceplate). Once the turbulent puff fully forms and reacts (Figure 6(c)), the flame structure in the puff becomes more complex, the layers interacts and the overall $\mathrm{OH}$ becomes more distributed. Subsequently, the ejected mixture is consumed and forms a distributed $\mathrm{OH}$ region (Figure 6(d)) that gradually disappear (Figure 6(e) - the $\mathrm{OH}$ intensity gradually decreases), until complete burn out occurs as the complete disappearance of $\mathrm{OH}$ suggests (Figure 6(f)). Note that as the chemiluminescence sequences suggested previously, complete extinction can indeed occur: in the instance shown in Figure 6(f) the reaction zone fully disappear from the imaging plane. This stage is consistently observed in our system. 


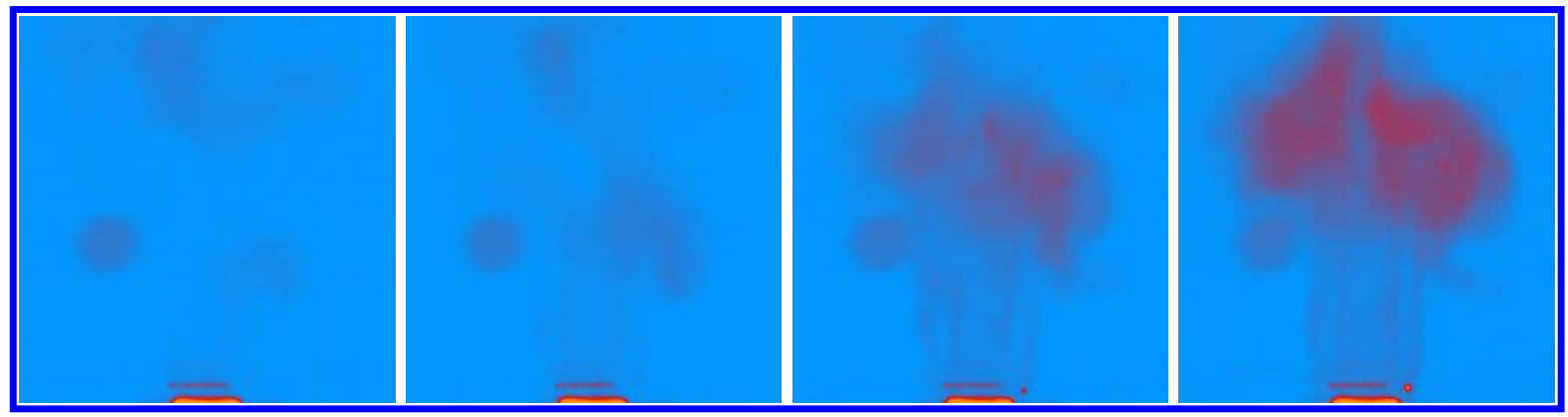

(a)

(b)

(c)

(d)

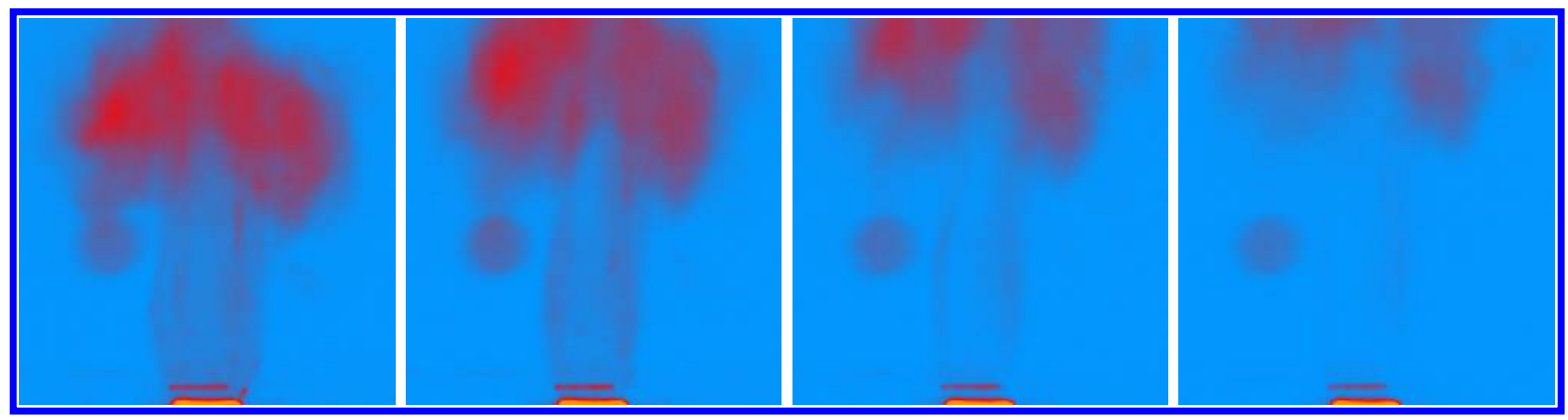

(e)

(f)

(g)

(h)

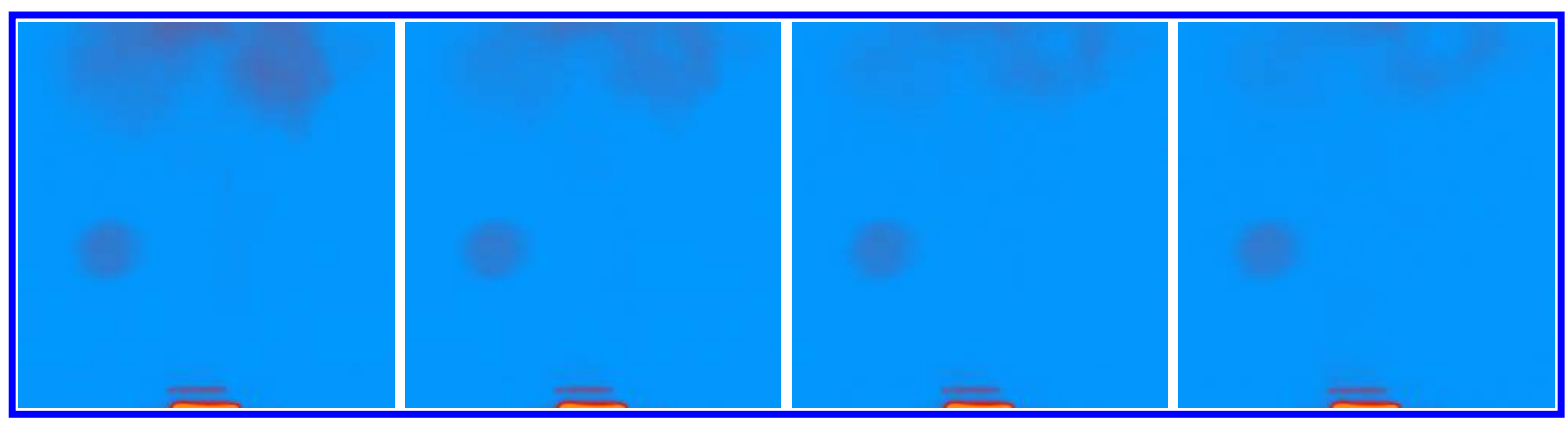

(i)

(j)

(k)

(1)

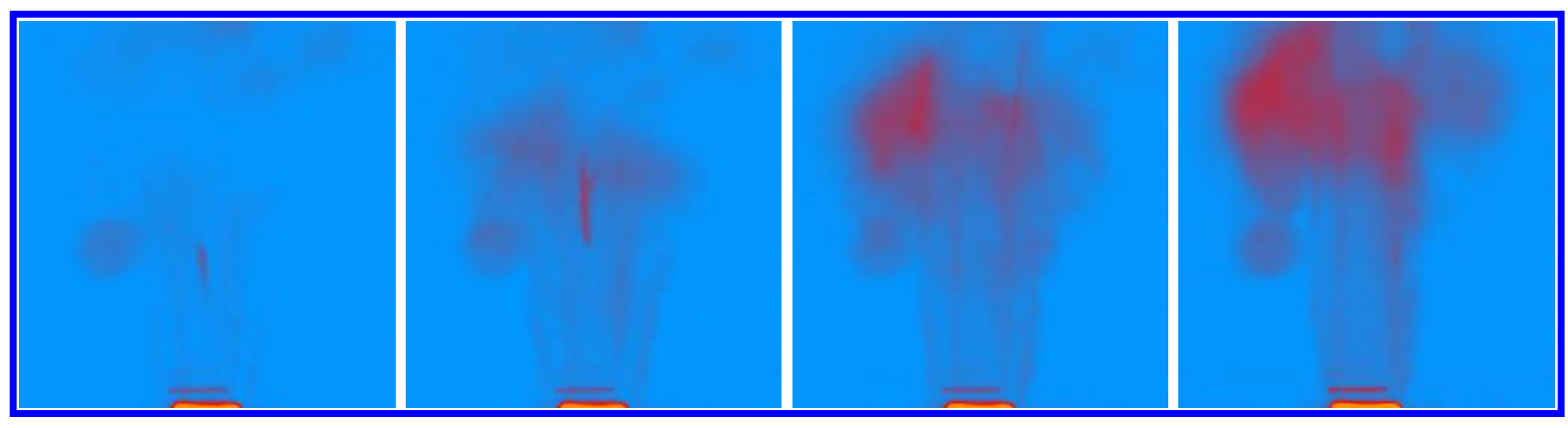

(n)

(o)

(p)

Figure 5. Sequence of false colored instantaneous chemiluminescence images for unsteady operation at $\phi=0.3$ and $\Delta v=38 \mathrm{~m} / \mathrm{s}$. The time separation between images is $100 \mu \mathrm{s}$, and the exposure time was set to $97.25 \mu$ s. The spot on the left hand side of each images is due to the reflection of the hot injector on the window. The bright region in the center at the bottom of the frame is the hot injector rim.

\section{Chamber pressure fluctuations}

High-speed chamber pressure measurements were taken simultaneously with the $\mathrm{OH}^{*}$ chemiluminescence images. Pressure measurements were taken at a single point on the side of the combustion chamber at 105 $\mathrm{mm}$ downstream of the injector faceplate. An example of the pressure fluctuation measured for a case at 


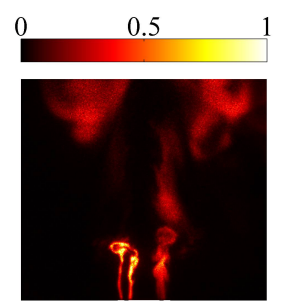

a)

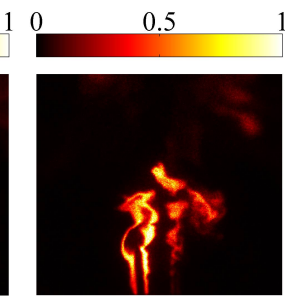

b)

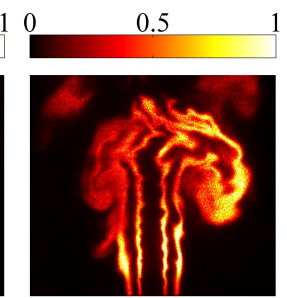

c)

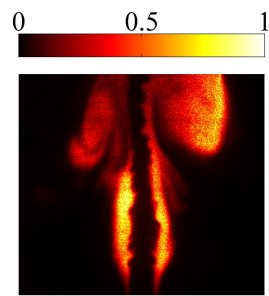

d)

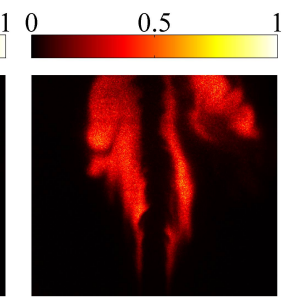

e)

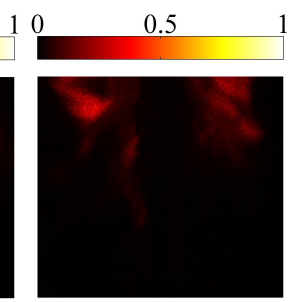

f)

Figure 6. PLIF images for an unsteady flame showing a sequence of 6 instantaneous uncorrelated images for the unsteady case at $\phi=0.3$ and $\Delta v=-38 \mathrm{~m} / \mathrm{s}$. The position of the coaxial injector is shown in image (a). The relatively darker region at the bottom of the image is due to reflections from the injector block that could not be corrected for. All PLIF images have been equally scaled in the [0,1] range.

$\phi=0.1$ was shown in the inset of Figure 2. Generally, we observe a well-defined periodic pressure oscillation, with typical amplitudes in the range $1-2 \%$ of the mean pressure value, associated with the unsteady operation under lean conditions. In spite of the small amplitude of the pressure fluctuation, the global structure of the flame undergoes drastic changes over the period. This pressure fluctuation value is below the threshold classically taken to separate stable from unstable operation of combustion chambers; ${ }^{16}$ nevertheless, it clearly demonstrates that drastic flame fluctuations can be associated to much smaller pressure variations.

The temporal measurements of pressure and chemiluminescence were used to extract the characteristic frequencies associated with the unsteady flame dynamics. Figures $7(\mathrm{a})$ and $7(\mathrm{~b})$ show the power spectral density obtained from the pressure fluctuation and chemiluminescence data, respectively, for the case at $\phi=0.1$. For the chemiluminescence data, the chemiluminescence intensity in each image of the time sequence was integrated over the full frame to define the frame-averaged intensity; spectra were then computed from the time series of the frame-averaged intensity. The existence of well-defined preferred frequencies in these spectra demonstrates the well-established periodic nature of the flame. Both the pressure and chemiluminescence give the same frequency signature. From the spectra we can identify several frequencies whose magnitudes are significantly higher than the baseline. We here indicate them as $\mathrm{f}_{0}, \mathrm{f}_{00}, \mathrm{f}_{1}, \mathrm{f}_{2}$ and $\mathrm{f}_{3}$. Frequencies $\mathrm{f}_{2}, \mathrm{f}_{3}$ and following peaks are harmonics of the fundamental frequency $f_{1}$. Other frequency peaks (or groups) can be identified in the spectra; however, at the current time they could not be associated with any physical process occurring in the chamber since they were somewhat independent of chamber length and other injection parameters. For the particular case shown in these figures, $\mathrm{f}_{0} \approx 90 \mathrm{~Hz}$ while $\mathrm{f}_{1} \approx 1 \mathrm{kHz}$. We will discuss the properties of these identified preferred frequencies subsequently.

Figure 8 compares the spectrum obtained from the pressure and chemiluminescence data. The data shown in Figure 8(b) is the same as that shown in Figure 8(a), but the frequency axis in the spectra has been normalized by their $f_{1}$ frequencies to emphasize the different harmonics. The spectra demonstrate that the frequencies obtained from both pressure and chemiluminescence correspond well. The strongest frequencies (e.g., $\mathrm{f}_{0}$ or $\mathrm{f}_{1}$ ) are well captured by both. The pressure spectrum captures a finer range of intermediate frequencies, which can also be identified in the chemiluminescence spectrum after close inspection. In general, the chemiluminescence spectrum is more selective in identifying the dominant frequency and its harmonics as compared to the pressure spectrum. On the contrary, the pressure trace tends to attenuate the harmonic frequencies; this could also be due to a response attenuation of the pressure transducer at high frequencies and by the method used to mount it on the rocket combustor wall. Therefore, overall both quantities can be used to characterize the flame dynamics with equal confidence.

\section{Effect of varying chamber length}

To further investigate the nature of frequencies observed in Figure 7, the response of the flame as the length of the chamber was varied, while all other test conditions were kept the same, was investigated. The initial experiments to understand the influence of chamber length presented here were performed at an equivalence ratio of 0.1 (Group 1 in the table) to keep a lower combustor temperature, thus allowing more and longer runs.

With decreasing chamber length $L_{c}$, the mean chamber pressure remains almost constant (Figure 9(a)), while the amplitude of the pressure fluctuations decreases gradually (Figure 9(b)). In general the pressure 


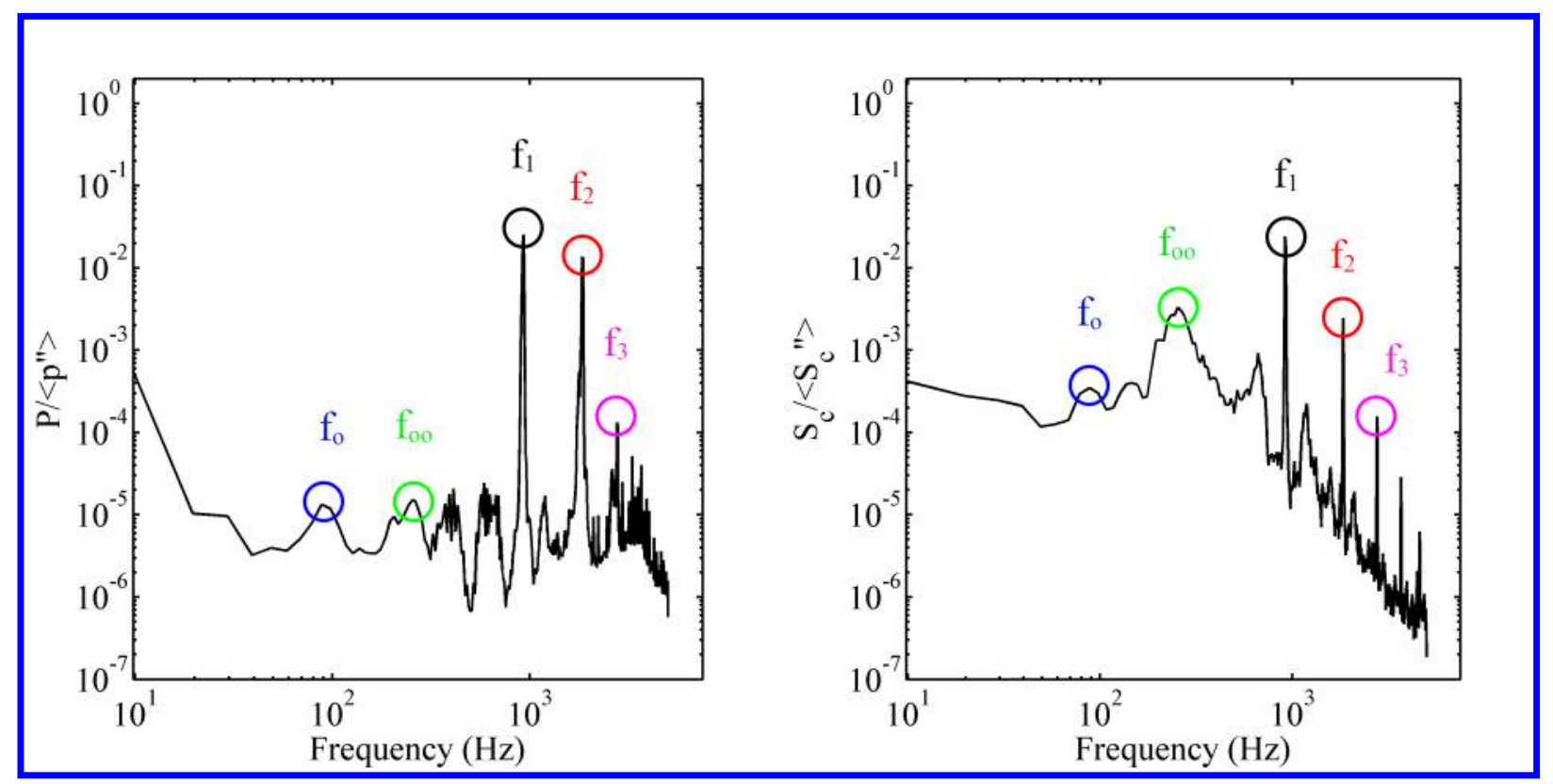

(a)

(b)

Figure 7. (a) Pressure fluctuation and (b) frame-integrated chemiluminescence spectra for a case $\phi=0.1$ case.

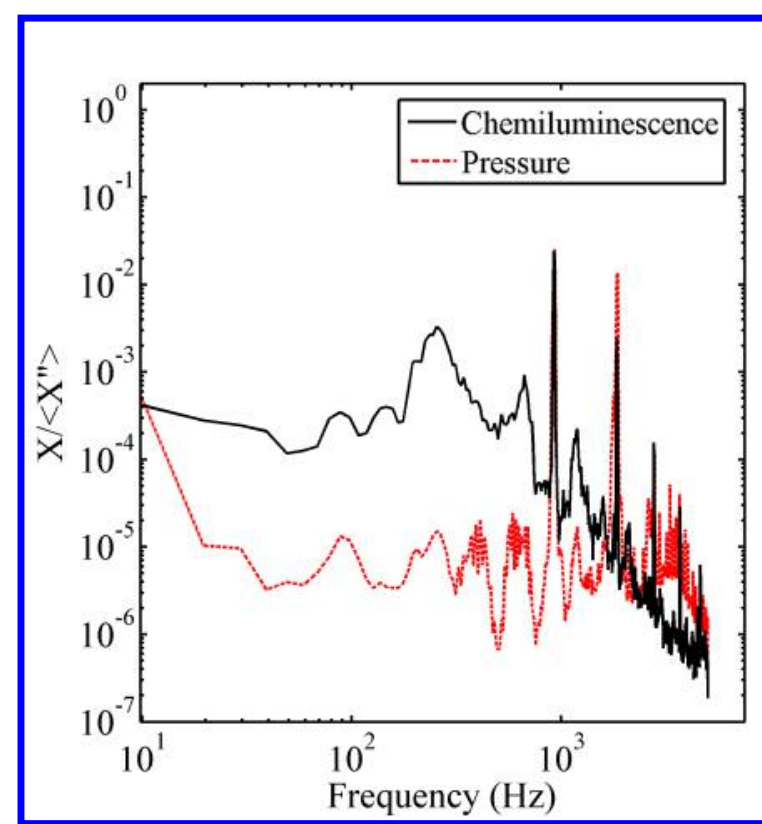

(a)

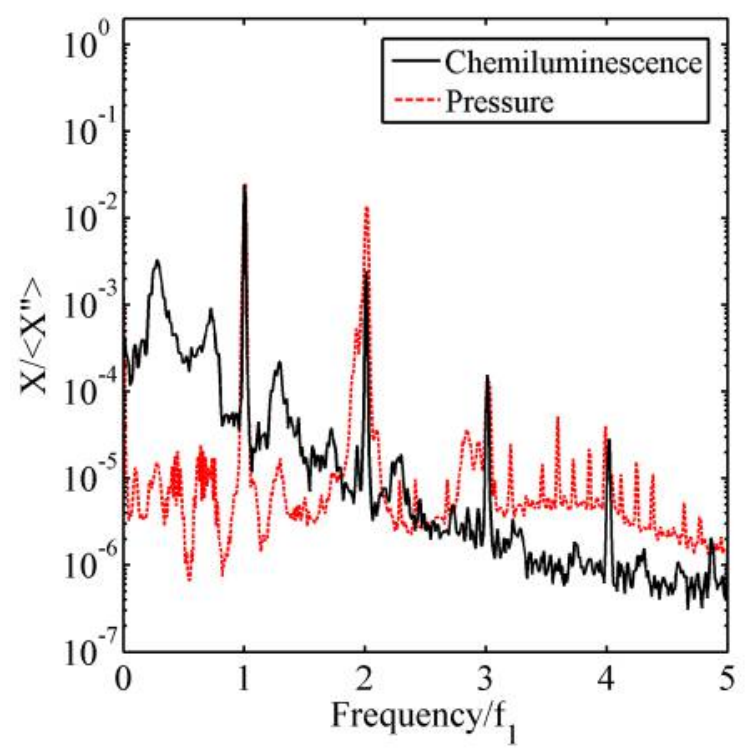

(b)

Figure 8. Comparison of pressure (dashed red) and frame-integrated chemiluminescence (black) spectra for a $\phi=0.1$ case. Part (b) is equivalent to part (a) after the frequency axis has been scaled by $\mathbf{f}_{1}$. 


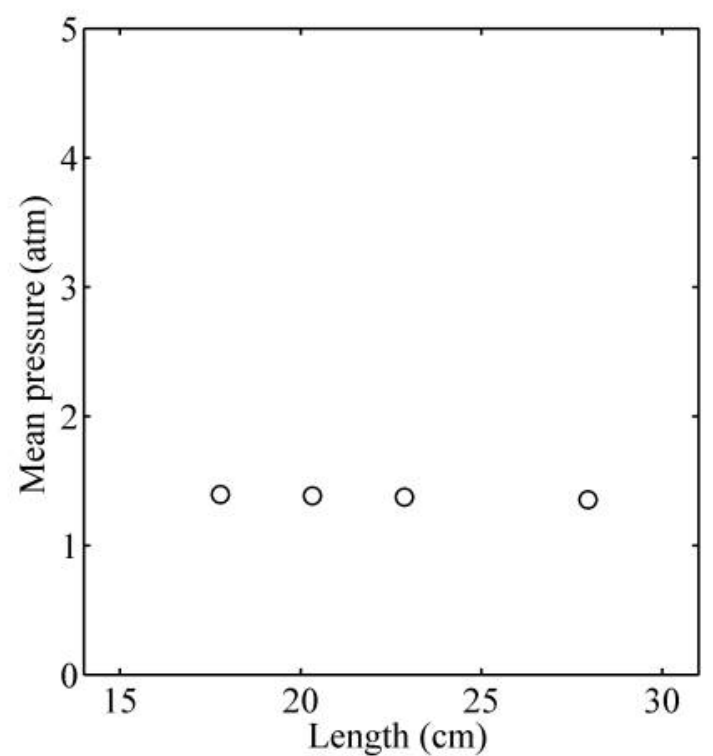

(a)

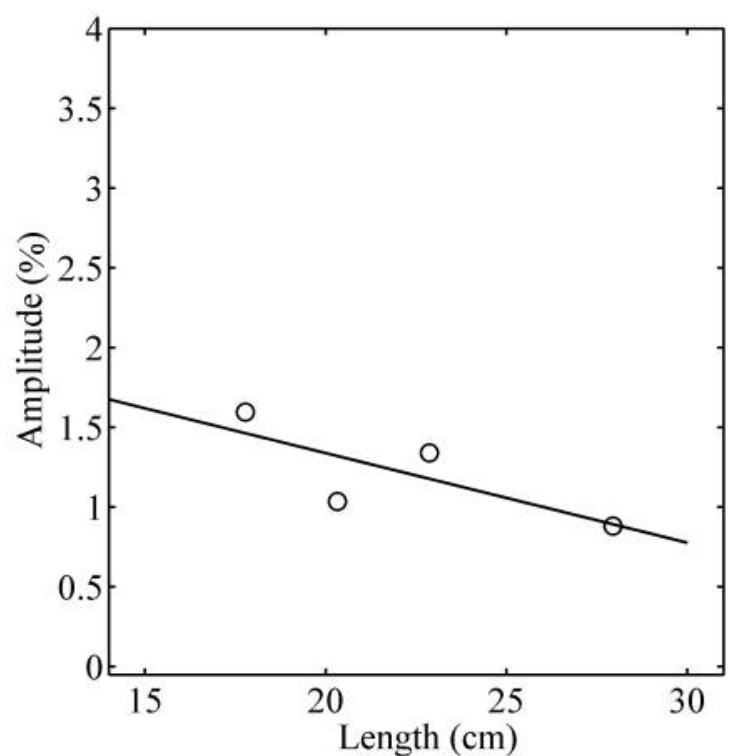

(b)

Figure 9. Variation in (a) mean chamber pressure and (b) pressure fluctuation amplitude with chamber length. These results are for a case belonging to Group $1(\phi=0.1)$ with a $\dot{m}=0.73 \mathrm{~g} / \mathrm{s}$.

fluctuation amplitude remain in the $1-2 \%$ range. When the chamber length is decreased beyond a certain value, all other conditions remaining the same, the flame is observed to become steady. For the case considered here this limiting chamber length was found to be near $L_{c}=7 \mathrm{in}$. This transition from unsteady to steady is visible in the spectral density plots, pressure fluctuation plots and chemiluminescence plots. Figure 10 shows the pressure fluctuation for the same case considered thus far at different chamber lengths. Multiple runs at a chamber length of 7 in resulted in observation of an unsteady flame during some runs and steady during others. All runs above this length were always unsteady and below this were always steady. This shows that a critical chamber length could exist, below which a flame is always steady under a given set of conditions. Figure 10(d) shows the pressure fluctuation in the chamber from a run when the flame was steady in a 7 in long chamber.

For all the unsteady cases, the dominant frequencies (highlighted in Figure 7) were extracted as a function of the chamber length and are summarized in Figure 11 (shown as a function of $1 / L_{c}$ ). It is observed that $f_{0}$ and $f_{00}$ remain constant with varying lengths and $f_{00}$ is always approximately three times the value of $\mathrm{f}_{0} . \mathrm{f}_{1}, \mathrm{f}_{2}$ and $\mathrm{f}_{3}$ vary inversely with the length. Inverse dependence of $\mathrm{f}_{1}, \mathrm{f}_{2}$ and $\mathrm{f}_{3}$ on the chamber length suggests that these frequencies are associated with longitudinal thermoacoustic modes, and could be considered a screeching mode. They are thus what in the literature are typically referred to as the L1, L2, etc frequencies. ${ }^{16} \mathrm{f}_{0}$ and $\mathrm{f}_{0} 0$, which do not depend on $L_{c}$, could be entropy modes or other transverse modes. Further analysis is required to understand what these frequencies actually represent in this system.

\section{Combustion instability and side-jet formation in variable-density, nonreacting coaxial jets}

The analysis carried out so far indicates that there is a well-defined periodic variation in the combustion properties in the chamber. The main instability mode seems to be associated with a longitudinal acoustic mode and it strongly couples with the dynamics of the flame. Ultimately, the flame undergoes this periodic cycling between ignition, consumption and extinction. In an attempt to link the observed behavior to possible causes (e.g., local fluctuations of fuel/oxidizer, equivalence ratio, etc), we have considered the properties, and in particular the mixing field, of variable-density, turbulent non-reacting coaxial jets. The results of this part of the study are described more in detail in our companion work; ${ }^{22}$ here we report only the main result. From mixture measurements of the flowfield generated by coaxial injection of different molecular weight (i.e., different initial density) fluids we identify the formation of what are referred to as "side jets" under certain coaxial injection configurations. Side jets are self-excited, periodic, radial ejections or spreading of the jet 


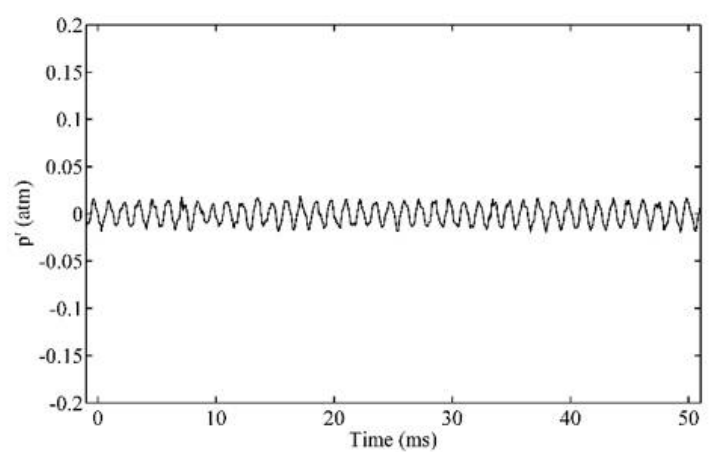

(a)

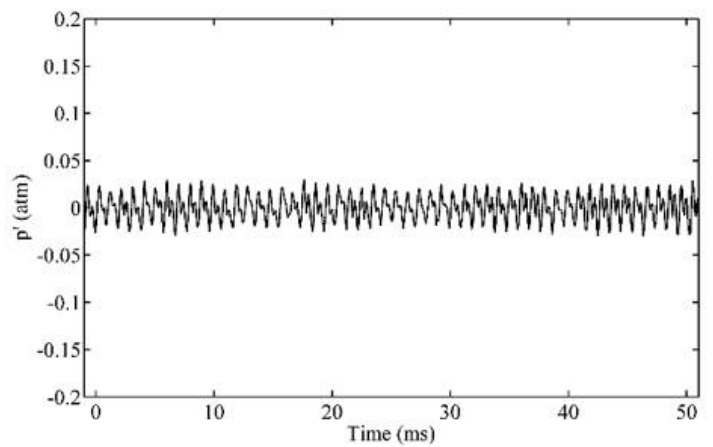

(c)

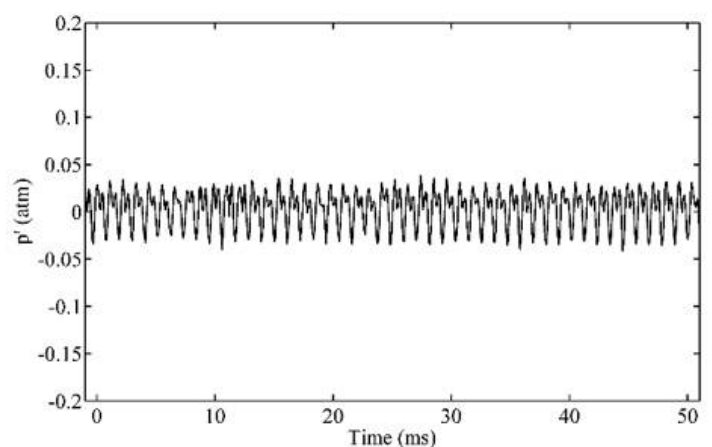

(b)

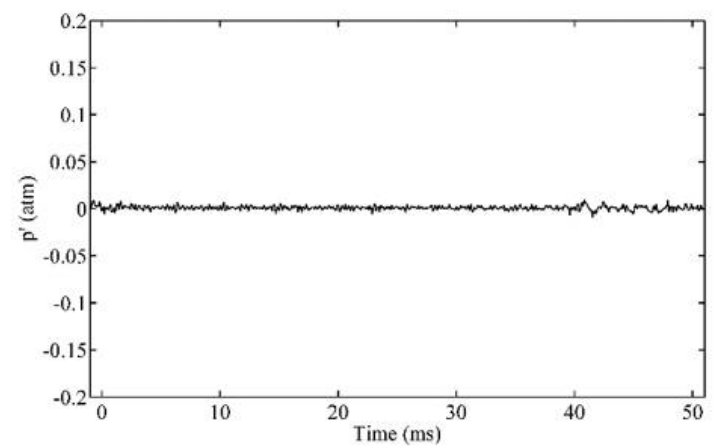

(d)

Figure 10. Pressure fluctuation for $\phi=0.1$ with a chamber length of (a) 11 in (b) 9 in (c) 8 in and (d) 7 in.

column. They have been observed in isolated low-density jets issued into a quiescent environment, ${ }^{33-35}$ and we also observe them in our configuration. Figure 12 compares the turbulent structure of non-reacting coaxial jets as visualized by a planar measurement of the local mole fraction of inner-fluid (using a tracer-based PLIF technique). The two cases refer to a case where a stationary turbulent flowfield without any side jet is observed (Figure 12(a)), and to a case where hydrodynamic instability induces the side jets (Figure 12(b)) - a side jet can be recognized as the rich region on the side of the coaxial jet in outer-fluid (the blue and red regions on the left of the main coaxial jet column). The two cases differ for the combination of fluid used (argon/nitrogen for case on the left, nitrogen/helium for the case on the right). The onset of the side jets appears to be associated with both the (inner-to-outer) velocity and density ratios, $R=v_{i} / v_{o}$ and $S=\rho_{i} / \rho_{o}$; however, their combined effect is captured by the (inner-to-outer) momentum flux ratio $J=S R^{2}$. When $J$ is larger than about 15, variable-density coaxial jets are found to have some form of instability that results in the formation of side jets as seen in Figure 12(b). On the contrary, when the value of $J$ is less than 15, the side jets disappear and a stationary flow structure, like the one shown in Figure 12(a) is observed.

The values of the $(R, S)$ combinations used to generate the two cases shown in Figure 12 were selected to closely match the corresponding $(R, S)$ combinations of reacting cases that were steady or unsteady; in particular, they were selected to represent the cases shown in Figure 4. Thus, the onset of the hydrodynamic instability that leads to side jet formation in non-reacting variable-density coaxial jets represents well the onset of the thermoacoustic instability. The exact nature of the hydrodynamic instability, how it is modified by heat release, and how it couples with the acoustic and combustion properties of the system is currently not known. We are continuing to investigate the stability properties of variable-density coaxial jets (reacting and non-reacting) in an attempt to answer these questions. 


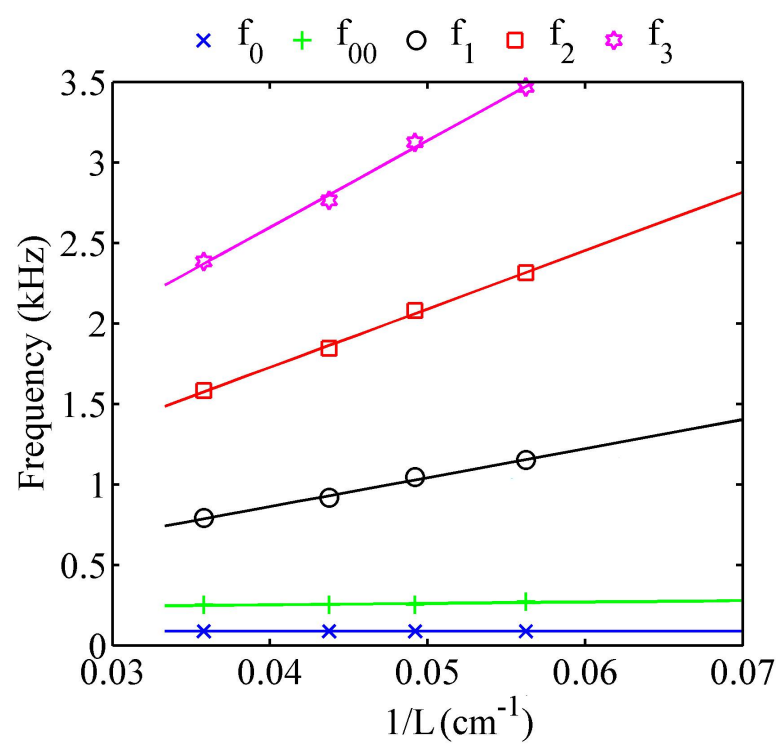

Figure 11. Variation of pressure fluctuation frequency with chamber length for the $\phi=0.1$ case.

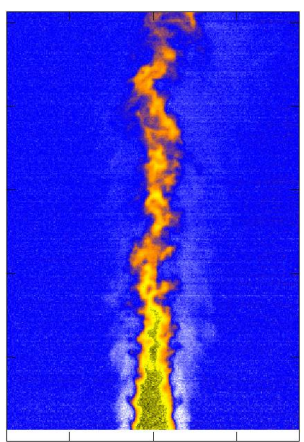

(a)

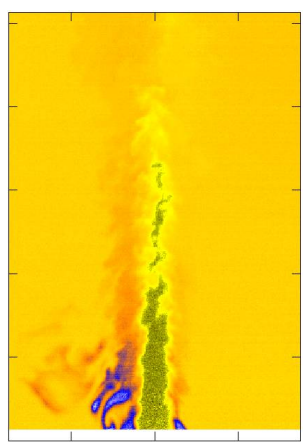

(b)

Figure 12. Inner-fluid mole fraction images of typical cases (a) without and (b) with side jets. Case (a) refers to argon/nitrogen injection, while (b) to nitrogen/helium injection.

\section{Conclusion and Outlook}

Shear coaxial $\mathrm{GH}_{2} / \mathrm{GO}_{2}$ jet flame experiments were performed at the Michigan Single Element Injector Facility. Chamber conditions are characterized using $\mathrm{OH}^{*}$ chemiluminescence, OH PLIF, and high frequency pressure transducer measurements. From the observation of operating conditions within the chamber, a relation between the flame lift-off and the velocity difference of the propellant streams is established. Selfsustaining unsteady combustion is observed at fuel lean conditions. By performing experiments at varying chamber lengths, the instability is shown to be thermoacoustic in nature and related to longitudinal acoustic modes. Other frequency components are also observed, but their origin in the our setup is not understood at this time. Further analysis is need to understand their source.

Non-reacting experiments with different inner-to-outer stream density and velocity ratios were also conducted. The results show the presence of self-excited instabilities that result in side jets at higher values of density and velocity ratios (or alternatively, for momentum flux ratios larger than 15).

Future work at this facility intends to study the self-sustaining, unsteady combustion phenomena in both attached and lifted flames, in addition to flame stabilization processes. Implementing simultaneous PLIF and PIV measurements, which is our short term goal, would help produce measurements of flame location 
and flowfield properties during the relevant unsteady combustion processes. High-speed measurements and imaging are expected to provide a better understanding of the evolution and structure of side jets in nonreacting coaxial jets and of the unsteady flame in reacting cases. This would help explore the relationship between thermoacoustic instabilities in reacting cases and hydrodynamic instabilities in non-reacting cases.

\section{Acknowledgments}

The authors would like to thank Dr. Campbell D. Carter, Air Force Research Laboratory, WrightPatterson Air Force Base, $\mathrm{OH}$ for lending the Andor iXon EMCCD camera. This work is supported by NASA Marshall Space Flight Center under grant no. NNM13AA11G with P. Kevin Tucker as Technical Mentor.

\section{References}

${ }^{1}$ Culick, F. E. C. and Yang, V., "Overview of Combustion Instabilities in Liquid-Propellant Rocket Engines," Liquid Rocket Engine Combustion Instability Progress in Astronautics and Aeronautics, Vol. 169, AIAA, Washington, DC, 169th ed., 1995, pp. 3-37.

${ }^{2}$ Rayleigh, J. W. S., "The Explanation of Certain Acoustical Phenomena," Nature, Vol. 18, No. 319, 1878, pp. $319=321$.

${ }^{3}$ Crocco, L. and Cheng, S.-I., Theory of Combustion Instability in Liquid Propellant Rocket Motors, AGARDograph, Butterworths Scientific Publications, London, 1956.

${ }^{4}$ Culick, F. E. C., "Unsteady Motions in Combustion Chambers for Propulsion Systems," NATO RTO-AG-AVT-039, AGARDograph, 2006, p. 664.

$\checkmark 5$ Lieuwen, T. C., Unsteady Combustor Physics, Cambridge university Press, 2012.

${ }^{6}$ Rosen, S. C., Combustion instabilities in the transition region of an unstable model rocket combustor, Ph.D. thesis, Ann Arbor, 2011.

${ }^{7}$ Dasari, A., White, L. W., Abul-Huda, Y. M., and Gamba, M., "Experimental Characterization of the Flowfield and Flame Structure in a Rocket Combustor Using OH-PLIF," Proceedings of the Combustion Institute - Canadian Section, Windsor, CA, 2014, p. 6.

${ }^{8}$ Broda, J. C., Seo, S., Santoro, R. J., Shirhattikar, G., and Yang, V., "An experimental study of combustion dynamics of a premixed swirl injector," Symposium (International) on Combustion, Vol. 27, No. 2, 1998, pp. 1849-1856.

${ }^{9}$ Fritsche, D., Füri, M., and Boulouchos, K., "An experimental investigation of thermoacoustic instabilities in a premixed swirl-stabilized flame," Combustion and Flame, Vol. 151, No. 12, Oct. 2007, pp. 29-36.

$\checkmark{ }^{10}$ Lee, J. G., Kim, K., and Santavicca, D. A., "Measurement of equivalence ratio fluctuation and its effect on heat release during unstable combustion," Proceedings of the Combustion Institute, Vol. 28, No. 1, 2000, pp. 415-421.

${ }^{11}$ Lieuwen, T. C. and Zinn, B. T., "The role of equivalence ratio oscillations in driving combustion instabilities in low NOx gas turbines," Symposium (International) on Combustion, Vol. 27, No. 2, 1998, pp. 1809-1816.

${ }^{12}$ Samaniego, J. M., Yip, B., Poinsot, T., and Candel, S., "Low-frequency combustion instability mechanisms in a side-dump combustor," Combustion and Flame, Vol. 94, No. 4, Sept. 1993, pp. 363-380.

$\checkmark{ }^{13}$ Venkataraman, K. K., Preston, L. H., Simons, D. W., Lee, B. J., Lee, J. G., and Santavicca, D. A., "Mechanism of Combustion Instability in a Lean Premixed Dump Combustor," Journal of Propulsion and Power, Vol. 15, No. 6, Nov. 1999, pp. 909-918.

${ }^{14}$ Bellows, B. D., Bobba, M. K., Seitzman, J. M., and Lieuwen, T. C., "Nonlinear Flame Transfer Function Characteristics in a Swirl-Stabilized Combustor," Journal of Engineering for Gas Turbines and Power, Vol. 129, No. 4, Dec. 2006 , pp. $954-961$.

${ }^{15}$ Lieuwen, T. C., "Experimental Investigation of Limit-Cycle Oscillations in an Unstable Gas Turbine Combustor," Journal of Propulsion and Power, Vol. 18, No. 1, Jan. 2002, pp. 61-67.

${ }^{16}$ Sutton, G. P. and Biblarz, O., Rocket Propulsion Elements, Wiley-Interscience, 7th ed., 2000.

${ }^{17}$ Haidn, O. J., "Advanced rocket engine," Advances on propulsion technology for high-speed aircraft, RTO-EN-AVT-150, 2008.

${ }^{18}$ Harrje, D. T. and Reardon, F. H., "Liquid propellant rocket combustion instability," $N A S A-S P-194$, NASA, Washington, DC, 1972, p. 657 .

$\checkmark{ }^{19}$ Knapp, B., Farago, Z., and Oschwald, M., "Interaction of LOX/GH2 Spray-Combustion with Acoustics," 45th AIAA Aerospace Sciences Meeting and Exhibit, Aerospace Sciences Meetings, American Institute of Aeronautics and Astronautics, Jan. 2007.

${ }^{20}$ Oschwald, M., Knapp, B., Sliphorst, M., and Marpert, M., "Combustion Chamber Acoustics and Its Interaction with LOX/H2- and LOX/CH4-Spray Flames," Transactions of the Japan Society for Aeronautical and Space Sciences, Space technology Japan, Vol. 7, No. 26, 2009, pp. 97-103.

${ }^{21}$ Richecoeur, F., Ducruix, S., and Candel, S., "A Velocity Coupling Model for High Frequency Instabilities," 2nd European Conference for Aerospace Sciences (EUCASS), 2007.

22 Dasari, A. and Gamba, M., "Characterization of Unsteady Combustion Phenomena in a University Scale Rocket Combustor," To be presented at the 2015 AIAA SciTech Conference, 2015.

${ }^{23}$ Schumaker, S. A. and Driscoll, J. F., "Coaxial turbulent jet flames: Scaling relations for measured stoichiometric mixing lengths," Proceedings of the Combustion Institute, Vol. 32, No. 2, 2009, pp. 1655-1662. 
${ }^{24}$ Schumaker, S. A. and Driscoll, J. F., "Mixing properties of coaxial jets with large velocity ratios and large inverse density ratios," Physics of Fluids (1994-present), Vol. 24, No. 5, 2012.

${ }^{25}$ Schumaker, S. A., An Experimental Investigation of Reacting and Nonreacting Coaxial Jet Mixing in a Laboratory Rocket Engine, Ph.D. thesis, University of Michigan, Ann Arbor, 2009.

-26 Moser, M. D., Merenich, J., Pal, S., and Santoro, R. J., "OH-radical imaging and velocity field measurements in a gaseous hydrogen/oxygen rocket," 29th Joint Propulsion Conference and Exhibit, Joint Propulsion Conferences, American Institute of Aeronautics and Astronautics, June 1993.

-27Santoro, R. J., Pal, S., Woodward, R., and Schaaf, L., "Rocket Testing at University Facilities," 39th Aerospace Sciences Meeting and Exhibit, Aerospace Sciences Meetings, American Institute of Aeronautics and Astronautics, Reno, NV, Jan. 2001, p. 16.

${ }^{28}$ Hutt, J. and Cramer, J., "Advanced rocket injector development at the Marshall Space Flight Center," Space Programs and Technologies Conference, SPACE Conferences \& Exposition, American Institute of Aeronautics and Astronautics, Sept. 1996.

${ }^{29}$ Clemens, N. T., "Flow Imaging," Encyclopedia of Imaging Science and Technology, 2002.

$\checkmark{ }^{30}$ Koban, W., Koch, J. D., Hanson, R. K., and Schulz, C., "Toluene LIF at elevated temperatures: implications for fuelair ratio measurements," Applied Physics B, Vol. 80, No. 2, 2005, pp. 147-150.

${ }^{31}$ Schulz, C. and Sick, V., "Tracer-LIF diagnostics: quantitative measurement of fuel concentration, temperature and fuel/air ratio in practical combustion systems," Progress in Energy and Combustion Science, Vol. 31, No. 1, 2005, pp. 75-121.

\$2 Johari, H., Zhang, Q., Rose, M. J., and Bourque, S. M., "Impulsively started turbulent jets," AIAA Journal, Vol. 35, No. 4, 1997, pp. 657-662.

33 Monkewitz, P. A. and Sohn, K. D., "Absolute instability in hot jets," AIAA Journal, Vol. 26, No. 8, Aug. 1988, pp. 911916.

${ }^{34}$ Sreenivasan, K. R., Raghu, S., and Kyle, D. M., "Absolute instability in variable density round jets," Experiments in Fluids, Vol. 7, No. 5, 1989, pp. 309-317.

${ }^{35}$ Kyle, D. M. and Sreenivasan, K. R., "The instability and breakdown of a round variable-density jet," Journal of Fluid Mechanics, Vol. 249, 1993, pp. 619-664. 
This article has been cited by:

1. Abhinav Dasari, Mirko GambaVariation of Dominant Instability Mode with Fuel Configuration in an Inverted Coaxial Injector . [Citation] [PDF] [PDF Plus]

2. Abhinav Dasari, Mirko GambaCharacterization of Unsteady Combustion Phenomena in a University Scale Rocket Combustor . [Citation] [PDF] [PDF Plus] 